\title{
ESTILO DE LIDERANÇA E DESEMPENHO CRIATIVO EM EQUIPES DE TELEJORNALISMO: um estudo em emissoras de TV cearenses
}

\section{1- Vivianne Pereira Salas Roldan*}

Mestre em Administração e Controladoria pela Universidade Federal do Ceará (UFC), Brasil.

Professora do Centro de Treinamento e Desenvolvimento (CETREDE) e tutora a distância do Instituto UFC Virtual. vsalasroldan@gmail.com

http://lattes.cnpq.br/5442727125123489

\section{2- Augusto Cézar de Aquino Cabral}

Doutor em Administração pela Universidade Federal de Minas Gerais (UFMG), Brasil.

Professor do Programa de Pós-Graduação em Administração e Controladoria da Universidade Federal do Ceará (UFC), Brasil.

cabral@ufc.br

http://lattes.cnpq.br/7080799282119351

\section{3- Maria Naiula Monteiro Pessoa}

Doutora em Engenharia da Produção pela Universidade Federal de Santa Catarina (UFSC), Brasil.

Professora do Programa de Pós-Graduação em Administração e Controladoria da Universidade Federal do Ceará (UFC), Brasil.

naiula@ufc.br

http://lattes.cnpq.br/5840627785299914

\section{4- Rodrigo Bandeira-de-Mello}

Doutorado em Engenharia de Produção pela Universidade Federal de Santa Catarina (UFSC), Brasil.

Professor Adjunto da Fundação Getulio Vargas (FGV-SP), Brasil

rodrigo.bandeira.demello@fgv.br

http://lattes.cnpq.br/4359650960250826

\section{5- Sandra Maria dos Santos}

Doutora em Economia pela Universidade Federal de Pernambuco (UFPE), Brasil.

Professora do Programa de Pós-Graduação em Administração e Controladoria da Universidade Federal do Ceará (UFC), Brasil.

smmsantos@ufc.br

http://lattes.cnpq.br/0740161704624013

\section{6- Tereza Cristina Batista de Lima}

\section{Tereza Cristina Batista de Lima}

Doutorado em Educação pela Universidade Federal do Ceará (UFC), Brasil.

Professora do Programa de Pós-Graduação em Administração e Controladoria da Universidade Federal do Ceará (UFC), Brasil.

tereza@prograd.ufc.br

http://lattes.cnpq.br/7117960824805237

\section{Diego Maganhotto Coraiola - Editor Geral}

Editor responsável pela submissão:

Deise Luiza da Silva Ferraz.

Artigo analisado via processo de revisão duplo cego (Double-blind).

Recebido em: 26/07/2013

Aprovado em: 02/09/2013

Última Alteração: 31/08/2013

* Contato Principal: Rua Margarida de Queiroz, 990. Cidade dos Funcionários, Fortaleza-CE, Brasil. CEP: $60822-530$. 


\title{
ESTILO DE LIDERANÇA E DESEMPENHO CRIATIVO EM EQUIPES DE TELEJORNALISMO: UM ESTUDO EM EMISSORAS DE TV CEARENSES
}

\section{RESUMO}

O estudo analisa a relação entre estilo de liderança e a promoção do comportamento criativo em equipes de trabalho de telejornalismo em três empresas de TVs cearenses. É de natureza qualitativa e descritiva quanto à finalidade, sendo utilizada uma estratégia mista de análise e coleta de dados. Os resultados da análise quantitativa sugerem que o estilo de liderança transformacional apresenta maior relação sobre o desempenho criativo das equipes, do que a liderança transacional. As reuniões se destacaram como a principal estratégia de liderança transacional, por meio das quais os gestores definem e acompanham o desempenho desejado pela organização, atendendo à gestão do risco criativo e operacional. Os erros não são tolerados no contexto televisivo, gerando punições. Incentivos não financeiros como treinamentos e ascensão de carreira são estratégias de recompensas ao comportamento criativo, utilizadas pelos gestores. Dentre as estratégias de liderança transformacional constatou-se o uso do empowerment e do estímulo à aprendizagem, que atende à necessidade de flexibilidade e autonomia no processo de produção dos programas jornalísticos. Apesar de todas as equipes se classificarem como "equipe dos sonhos", buscando ir além dos resultados almejados, coexiste conflitos relacionados ao estresse, controle criativo do processo, diferenças de acesso aos recursos, poder e prestígio.

\section{Palavras-Chave}

Estilo de Liderança, Desempenho criativo, Telejornalismo.

\section{LEADERSHIP STYLE AND CREATIVE PERFORMANCE IN TEAMS OF TV JOURNALISM: A STUDY IN CEARÁ'S TELEVISION STATIONS}

\begin{abstract}
The study examines the relationship between leadership style and the promotion of creative behavior in work teams of TV journalism in three companies TVs Ceará. It is qualitative and descriptive as to the purpose, being used a mixed strategy of analysis and data collection. The results of the quantitative analysis suggest that the transformational leadership style has a higher ratio on the performance of creative teams, than transactional leadership. The meeting stood out as the main strategy of transactional leadership, through which managers define and monitor the performance desired by the organization, given the risk management and operational creative. Mistakes are not tolerated in the context of television, generating punishments. Non-financial incentives such as training and ascension career are strategies to reward creative behavior, used by managers. Among the strategies for transformational leadership was found using the empowerment and encouragement to learning, which addresses the need for flexibility and autonomy in the production of news programs. Although all teams are classified as "dream team", seeking to go beyond the desired results, coexists conflicts related to stress, creative control of the process, differences in access to resources, power and prestige.
\end{abstract}

\section{Keywords}

Leadership Style, Performance creative, TV Journalism. 
Estilo de liderança e desempenho criativo em equipes de telejornalismo: um estudo em emissoras de TV cearenses

\section{Introdução}

Evidências sobre uma relação positiva entre a liderança, a inovação e a criatividade têm sido encontradas por pesquisadores, neutralizando as proposições que negam a sua existência. Apesar de constituírem ainda um corpo de estudo restrito, pesquisas diversas têm se preocupado em analisar a influência do líder sobre o comportamento criativo (Mumford, Scott, Gaddis, \& Strange, 2002).

Dentre essas pesquisas, constata-se que a Teoria da Nova Liderança tem sido uma das abordagens mais utilizadas, o que se dá desde a década de 90, conforme Dionne, Yammarino, Atwater e Spangler (2004). No campo teórico da Nova Liderança, os pesquisadores têm procurado estabelecer relações entre a liderança transformacional, transacional e carismática, a performance criativa dos colaboradores e a inovação. Contudo, segundo Pieterse, Knippenberg, Schippers e Stam (2010), esses estudos ainda não conseguiram comprovar de forma consistente qual desses estilos de liderança é mais eficaz.

A economia da cultura pode ser considerada um campo fecundo para o estudo da criatividade e sua gestão, dada as tensões na gestão do pessoal criativo e de processos criativos. Na gestão de pessoal criativo, os líderes têm que lidar com as tensões causadas pelos objetivos duplos de arte e comércio. No gerenciamento dos processos criativos, os líderes são desafiados a criar práticas de intervenção que promovam o sucesso organizacional (Defillippi, Grabher, \& Jones, 2007).

Na gestão de organizações culturais, está presente o paradoxo da autonomia e do controle. Se a empresa impuser uma direção em excesso, pode estreitar a busca por inovações. Se deixar a geração de novas idéias depender de um processo mais informal de trabalho, correrá o risco da ineficiência pela falta de controle (Björk, Boccardelli, \& Magnusson, 2010).

Considerando-se a lacuna de compreensão em torno da gestão da criatividade nas organizações culturais (Defillippi et al., 2007), relacionada à forma como os gestores lidam com os desafios da gestão de pessoal e processos criativos, e o gap dos estudos da Abordagem da Nova liderança em torno do estilo de liderança que possui maior relação com o desempenho criativo dos colaboradores, pretendeu-se responder ao seguinte problema: Qual estilo de liderança exerce maior influência sobre o desempenho criativo das equipes, no contexto do telejornalismo?

Como ponto de partida, foram definidas as seguintes hipóteses: 1) O estilo de liderança transformacional apresenta maior influência sobre o desempenho criativo das equipes; 2) O estilo de liderança transacional apresenta maior influência sobre o desempenho criativo das equipes; 3) Não há diferenças significativas entre os estilos de liderança sobre o desempenho criativo das equipes.

Como objetivo geral, a pesquisa pretendeu analisar a relação entre estilo de liderança e a promoção do comportamento criativo em equipes de trabalho de telejornalismo em três empresas de TVs cearenses: TV Assembléia, TV Jangadeiro e TV O POVO. Para isto, foram definidos os seguintes objetivos específicos: a) Analisar o desempenho criativo das equipes de Telejornalismo; b) Investigar a relação entre estilo de liderança e os fatores derivados da ação direta do líder; c) Verificar a relação entre estilo de liderança e os resultados da equipe; d) Identificar as estratégias de liderança utilizadas pelos gestores.

O artigo está dividido em cinco sessões. A introdução representa a primeira seção. Na segunda seção é apresentado o referencial teórico acerca do Modelo de Liderança Criativa de Rickards e Moger (2000), a literatura atual acerca da liderança transformacional e transacional, e a caracterização da indústria televisiva e o telejornalismo na economia da cultura. $\mathrm{Na}$ terceira seção é descrita a metodologia adotada no trabalho. Os resultados são apresentados na quarta seção, e na quinta seção são realizadas as considerações finais.

\section{Quadro Teórico}

\subsection{Liderança Criativa}

A liderança criativa é definida por Rickards e Moger (2000) como o processo de mudança do desempenho criativo da equipe de inaceitável para aceitável, e de aceitável para superior, desencadeado pela introdução de "estruturas benignas" que favoreçam a cooperação e a mutualidade. Para analisar esse processo os autores criaram o Modelo de Liderança Criativa (MLC). A criatividade e liderança são os elementos centrais do MLC, onde Rickards e Moger (2000) buscam distinguir as equipes com alto potencial criativo, daquelas com desempenho padrão ou esperado. Com o objetivo de mensurar os fatores de liderança criativa em equipes de criatividade e inovação, Rickards e Mogers (2000) criaram um instrumento de pesquisa, denominado "Team Factors Inventory" - TFI.

No MLC, Rickards e Mogers (2000) propõe sete fatores necessários para que se possam vencer as barreiras que interferem no processo de estruturação e alcance dos objetivos das equipes, denominados como "estruturas benignas". Esses fatores são derivados da ação direta do líder e de suas relações com os membros da equipe, são eles: plataforma de entendimento; visão compartilhada; clima; resiliência; idéias próprias; ativação em rede; e aprendizado vindo da experiência. Esses fatores compõem o questionário TFI - "Team Factors Inventory" ao qual os autores acrescentaram mais cinco variáveis: 1) três de resultado: produtividade, criatividade, e gerenciamento do conhecimento; e 2) duas de estilo de liderança: transacional e 
Vivianne Pereira Salas Roldan, Augusto Cézar de Aquino Cabral, Maria Naiula Monteiro Pessoa, Rodrigo Bandeira-de-Mello, Sandra Maria dos Santos, Tereza Cristina Batista de Lima

transformacional. Por meio dos fatores "estilo de liderança", Rickards e Mogers (2000) buscam identificar qual estilo associa-se à performance criativa.

\subsection{Os Sete Fatores de Liderança Criativa}

Na revisão de literatura em torno da criatividade, equipes e liderança, Rickards e Mogers (2000) constatam que boa parte dos estudos organizacionais tem dado maior ênfase à contribuição individual para a inovação, do que a gerada pela gestão e comportamento das equipes. Os autores buscam preencher essa lacuna, por meio do desenvolvimento de pesquisa em torno da questão. A plataforma de entendimento é o primeiro fator de liderança criativa de Rickards e Mogers (2000). O líder deve constituir para a equipe uma base de conhecimentos, crenças e pressupostos, a partir da qual ela deverá desenvolver novas idéias. Papéis e responsabilidades deverão ser definidos desde o início da estruturação da equipe.

A partir da análise da "plataforma de entendimento" pela equipe, serão geradas diversas perspectivas individuais em torno dela, cujo consenso criará uma "visão compartilhada" que proporcionará uma identificação e aceitação de novas idéias entre os membros. A equipe excepcional se destacará pela constituição de uma visão compartilhada inesperada, criativa. O terceiro fator do MLC consiste no "clima" psicológico ideal para a manutenção da criatividade nas equipes, onde o líder deverá promover uma relação de confiança (Rickards \& Mogers, 2000).

A "resiliência" é o quarto fator de liderança criativa, referindo-se à capacidade da equipe ser flexível diante das frustrações e adversidades, superando-as por meio da busca de novas perspectivas. O quinto fator do MLC é denominado "ideias próprias", se referindo ao comprometimento da equipe com as novas ideias (Rickards \& Mogers, 2000).

A “ativação em rede" é o sexto fator de liderança criativa, tratado por Rickards e Mogers (2000) como a capacidade da equipe de constituir contatos externos que the auxiliem a obter informações e recursos relevantes. Estudos diversos sugerem que equipes com nível elevado de desempenho e inovação, possuem elevada competência de comunicação externa (Van Woerkom \& Croon, 2009).

Conforme Van Woerkom e Croon (2009), as organizações só aprendem por meio do aprendizado concreto de suas equipes, no compartilhamento de conhecimentos e experiências. A capacidade das equipes de aprenderem com suas próprias experiências e erros, adaptando-se de forma contínua na solução de problemas criativos, consiste no sétimo fator de liderança criativa de Rickards e Mogers (2000), denominado "aprendizado vindo com a experiência". As intervenções do líder são essenciais para a promoção desse aprendizado pelas equipes.

\subsection{Criatividade}

Nesta seção, busca-se clarear o entendimento sobre o que é a criatividade no Modelo de Liderança Criativa de Rickards e Mogers (2000). No MLC, os autores focam a criatividade presente no contexto dos sistemas de redes sociais, domínios de problema e campos de empresas, seguindo a abordagem de autores como MacKinnon (1965), Amabile (1997), Csikszentmihalyi (1996, 1999), e Woodman et al. (1993). Rickards e Mogers (2000) abordam a criatividade das equipes, buscando compreender o que leva algumas equipes a ter um desempenho superior, que denominam como criativo, e outras a ter um desempenho padrão ou esperado.

Csikszentmihalyi (1996, 1999) defende que a criatividade deve ser compreendida como um fenômeno sistêmico, e não individual. A criatividade é resultante da interação entre os processos mentais do indivíduo e o contexto sociocultural no qual se encontra. Desse ponto de vista, é importante não apenas conceituar criatividade, mas investigar o contexto no qual ela se encontra, identificando como esse contexto reconhece a produção criativa. A criatividade é um processo resultante da intersecção de três fatores: indivíduo, domínio e campo.

O domínio se refere ao conhecimento acumulado e compartilhado no meio social, ao conjunto de regras e procedimentos simbólicos construídos no âmbito cultural. Mudanças no domínio podem ocorrer por meio das atitudes criativas dos indivíduos. Estes só conseguem interferir no domínio quando o conhecem com profundidade, identificando com facilidade os seus problemas, e buscando ampliar as suas fronteiras. Quanto mais estruturado o domínio, ou seja, quanto mais os seus princípios, procedimentos e informações forem claros e integrados, maior a possibilidade dos indivíduos conseguirem produzir inovações. Os indivíduos conseguirão criar respostas criativas satisfatórias em um determinado domínio, se conseguirem ter acesso amplo à informação a ele referente (Alencar \& Fleith, 2003).

Para Csikszentmihalyi (1999), o que é mais importante não é quantos indivíduos estão trazendo novas ideias e buscando modificar os domínios, mas sim a receptividade do campo à inovação pretendida. O campo consiste no conjunto de atores que atuam como juízes, decidindo se determinada ideia ou produto é criativo, e se merece ser incluído ou não no domínio.

Amabile (1997) e Woodman et al. (1993) concordam com a ideia de que as influências sociais e de contexto podem incentivar ou inibir a manifestação do talento criativo. Como formas de estimular a 
criatividade, Amabile sugere: estimular a autonomia, reduzindo o controle, e dando ênfase aos valores ao invés de regras; dar maior atenção a realizações, do que notas ou prêmios; proporcionar experiências que estimulem a criatividade, evitando situações de competição, e estimulando o prazer de aprender; fazer uso de um feedback informativo; fornecer alternativas de escolha; fazer com que as pessoas criativas sejam apresentadas como modelo (Amabile, 1983, 1989, 1996 apud Alencar \& Fleith, 2003).

Em sua teoria sobre criatividade, Amabile (1997) destaca como principais componentes da criatividade individual ou da pequena equipe: expertise, habilidade de pensamento criativo e motivação intrínseca para a tarefa. A autora destaca a autonomia, autodisciplina, orientação para tomada de riscos, tolerância para ambiguidade, perseverança diante de frustrações, entre outras, como características de personalidade geralmente encontradas em indivíduos criativos. No entanto, acredita que a criatividade ocorre mais provavelmente quando as habilidades dos indivíduos coincidem com a sua motivação intrínseca.

Rickards e Mogers (2000) consideram essa visão sistêmica e interacionista da criatividade, discutindo que é necessário que exista entre os membros da equipe uma base de conhecimento construída socialmente (plataforma de entendimento), de forma que tendo uma compreensão aprofundada desse domínio, tenham condições de elaborar novas ideias e projetos. Dessa forma desenvolverão uma "visão compartilhada" que poderá ser excepcional ou criativa. Os autores destacam em seu modelo a necessidade de um ambiente social favorável para a criatividade (clima) e a resiliência, comprometimento com novas ideias, capacidade de aprender com os próprios erros e de constituir contatos externos como habilidades individuais relevantes que deverão ser estimuladas pelo líder entre os membros de sua equipe.

\subsection{Liderança Transacional e Transformacional}

A liderança transformacional é aquela em que os líderes conseguem motivar os seus colaboradores para alcançarem um desempenho além do esperado, colocando os interesses da equipe e organização acima dos seus próprios (Bass, 1985).

Bass (1985) define que a liderança transformacional é composta por quatro componentes comportamentais inter-relacionados: a) motivação inspiradora: onde o líder desenvolve uma visão compartilhada, inspirando confiança, orgulho e respeito; b) estimulação intelectual: o líder promove a criatividade e inovação, provendo os subordinados com um fluxo estimulante de novas idéias, motivando-os para a busca de novas soluções; c) influência idealizada: onde o líder age como um modelo para os seus seguidores, fazendo uso de significados e estímulos para direcionar esforços e modelar comportamentos; e d) consideração individualizada: quando o líder atua como coaching e mentoring, delegando projetos para fomentar o aprendizado dos seguidores, e dando feedback contínuo.

Estudos em torno da liderança transformacional têm abordado mais sobre sua influência no desempenho individual do que no das equipes (Dionne et al., 2004). Kearney e Gebert (2009) pontuam que desde a década de 1990 crescem o número de estudos realizados em torno da liderança transformacional e carismática.

Contudo, explicam Pieterse et al. (2010), estudos empíricos em torno dessa questão ainda são escassos e inconsistentes, encontrando-se pesquisas que apresentam efeitos positivos e outras efeitos negativos. Dentre os estudos que destacam os efeitos positivos da liderança transformacional sobre o desempenho criativo dos subordinados se destacam: Jung, Chow e Wu (2003), Jung, Chow e Wu (2008), Gong, Huang e Farh (2009), Pieterse et al. (2010), e Lee (2011). Como ferramentas utilizadas pelos líderes transformacionais, esses estudos destacam o empowerment, o suporte do clima organizacional, o estímulo da motivação e aprendizagem, e a visão compartilhada em termos de valores organizacionais.

A liderança transacional é aquela que "ocorre quando o líder recompensa ou disciplina o liderado dependendo da adequação do seu desempenho" (Bass \& Avolio, 1994, p.4). Três fatores caracterizam a liderança transacional: 1) recompensas contingentes: o líder provê os subordinados com recompensas materiais e simbólicas conforme tenham alcançado as metas propostas, seguindo seu papel específico e exigências da tarefa; 2) gestão por exceção ativa: o líder exerce uma supervisão ativa do desempenho dos liderados para impedir as falhas antes que elas ocorram, tomando a ação corretiva necessária; 3) gestão por exceção passiva: o líder realiza a ação corretiva apenas após a ocorrência de desvios e erros (Bass \& Avolio, 1994).

As recompensas contingentes são de eficácia razoável na motivação dos liderados para alcance do melhor desempenho, quando comparadas com os fatores da liderança transformacional. Já a gestão por exceção tende a ser mais ineficaz, apesar de necessária em determinadas situações (Bass \& Avolio, 1994). Eisenberger e Shanock (2003) demonstram o impacto positivo das recompensas contingentes sobre o comportamento criativo dos liderados, argumentando que nas situações em que o indivíduo é orientado de que a criatividade produz recompensa, esta contribui para elevar o seu comportamento criativo.

Os estudos em torno da relação entre a liderança transacional e comportamento criativo dos subordinados também não chegaram a um consenso, apresentando também resultados ora positivos, ora negativos. Para Bass (1985) os melhores líderes são transformacionais e transacionais. Rickards e Clark (2006) explicam que nas pesquisas empíricas feitas por Bass com uso do MLQ (Multifactor Leadership Questionnaire), os resultados têm indicado que os líderes apresentam uma mistura de ambos os estilos de liderança, e que a liderança transformacional aumenta a eficácia da liderança transacional, mas não o substitui. 
Vivianne Pereira Salas Roldan, Augusto Cézar de Aquino Cabral, Maria Naiula Monteiro Pessoa, Rodrigo Bandeira-de-Mello, Sandra Maria dos Santos, Tereza Cristina Batista de Lima

\subsection{A Indústria Televisiva e o Telejornalismo na Economia da Cultura}

A indústria televisiva tem sido foco de vários estudos, no entanto, a literatura dedicada à gestão da televisão é limitada, tanto a nível doméstico como internacional. Pouco se sabe ainda sobre as práticas de gestão e tomada de decisão na televisão. Há, portanto, uma carência de pesquisas da área de administração em torno das indústrias de TV, principalmente no campo da liderança (Albarran, 2006).

A televisão pode ser compreendida como uma forma de comunicação em massa, com vários formatos e gêneros de programas, sendo o telejornalismo um dos gêneros sempre presentes na programação brasileira (Souza, 2004). O telejornalismo pode ser compreendido como a aplicação dos métodos e processos institucionalizados da área jornalística no meio televisivo, que orientam o formato final do conhecimento produzido, e o seu processo de produção (Ekström, 2002).

A unidade discursiva do sistema jornalístico é a notícia. Deve-se compreender a notícia como uma forma cultural específica de se lidar com a informação, assim como o próprio programa jornalístico é uma maneira cultural específica de se lidar com a notícia (Gomes, 2006). O programa jornalístico pode ser, portanto, considerado um produto valorizado pelo seu significado, conforme abordagem de Bendassolli, Wood, Kirschbaum, \& Cunha (2009).

O público é que concede à prática jornalística poder e legitimidade (Ekström, 2002), o que se alinha ao argumento de Bendassolli et al. (2009), de que o objeto cultural tem sua utilidade valorizada pela atribuição de valor do consumidor, no ato do consumo. Quanto ao formato, o programa jornalístico é visual, sendo produzido com o objetivo de ser apresentado e visualizado, levando sempre em consideração o espectador, aquele que irá “consumir" o produto jornalístico (Ekström, 2002).

O produto televisivo depende fortemente da confiança do cliente, constituindo-se em um risco para sua gestão, devido a necessidade da manutenção da economia de escala. Também, os produtos de mídia, como os programas jornalísticos, podem gerar externalidades socioculturais positivas e negativas (Reca, 2006).

Cada projeto desenvolvido na TV é considerado um produto único, e seu processo criativo evolui de maneira não formalizada, caracterizando-se pela incerteza de sua estrutura, dos recursos disponíveis, e dos resultados que serão obtidos. Os processos criativos se constituem em tarefas não-estruturadas como a fase inicial de geração de idéias e de desenvolvimento para a produção dos programas de TV. Nesses processos, também estão presentes tarefas não-criativas (Becker, Bergener, Schwehm \& Voigt, 2011 ).

A atividade dos jornalistas na TV exige um elevado esforço de coordenação temporal pela gestão. Os programas de TV possuem formato pré-determinado, devem estar prontos em um ponto específico do tempo, e são preparados, geralmente, com regularidade diária, denotando uma produção orientada pelas exigências de previsibilidade e controle (Ekström, 2002; Bonner, 2009).

Concomitante à necessidade de previsibilidade e controle, a flexibilidade é também um requisito essencial para o cumprimento do objetivo do telejornal. Fatos graves e inesperados podem ocorrer, impondo alterações no conteúdo e tempo da programação. Assuntos que antes possuíam uma importância de destaque podem passar a ter caráter secundário (Bonner, 2009).

Nesse contexto, a gestão do processo de produção assumirá diferentes formas, atuando em alguns momentos de forma desestruturada, para garantir flexibilidade. Em outros momentos, a gestão atuará de forma mais estruturada, em situações que irão requerer um maior planejamento, como a cobertura de acontecimentos com data marcada para acontecer (Bonner, 2009).

Na televisão, são os indivíduos criativos que dão origem à concepção e desenvolvimento dos produtos, como destacado por Bendassolli et al. (2009). Os processos criativos na TV se caracterizam ainda por serem altamente interativos, pois a "produção visual é um negócio de pessoas" (Becker et al., 2011, p.7), onde existe forte colaboração. Essa intensidade de colaboração está estreitamente relacionada com uma alta intensidade de comunicação, o que inclui os clientes.

O uso extensivo de equipes polivalentes, destacado por Bendassolli et al. (2009) para indústrias culturais, é um elemento presente na indústria televisiva. Estudos como o de Loon e Hemmingway (2005), Zaheer e Soda (2009) tratam a organização social do trabalho televisivo como fundamentada no trabalho em equipe, existindo rotação de funções e identificação com o trabalho flexível.

Como discutido por Caves (2003) para as indústrias criativas o risco de coordenação é elevado. Na concepção de Becker et al., (2011), os gestores da TV tem que enfrentar dois tipos de risco, o criativo e o operacional. Como risco criativo, destaca-se o risco de aceitação da platéia com relação às produções visuais. Esta é uma questão crítica para as TVs. Os riscos operacionais consistem nos riscos de ordem financeira, técnica, organizacionais ou de pessoal.

Outros riscos enfrentados pelas TVs são à instabilidade da demanda e o fenômeno de reconstrução mercadológica do consumidor (Bendassolli et al., 2009). As emissoras de televisão abertas sofrem atualmente com a incapacidade de garantir grandes audiências para os anunciantes, sua principal fonte de renda. Essa dificuldade é um reflexo do fenômeno de fragmentação das mídias, trazido pelos avanços tecnológicos, que acabaram minando a estrutura econômica e cultural das empresas de mídia (Gluck \& Sales, 2008). 
Assim como constatado por Bendassolli et al. (2009) no âmbito das indústrias culturais, estudos como o de Daymon (2000) e Hesmondhalgh e Baker (2008) revelam a presença de ambiguidades e conflitos no contexto televisivo. Em seu estudo, Daymon (2000) constata que a cultura organizacional da TV é de natureza fluida, onde a coesão, os conflitos e as diferenças coexistem.

Realizando uma pesquisa em um programa de televisão britânico, Hesmondhalgh e Baker (2008) obtiveram algumas constatações, entre elas: os trabalhadores da mídia televisiva possuem um forte poder de influência, prestígio e glamour em relação aos demais colaboradores com o mesmo salário; estresses e conflitos de interesses são comuns e estão relacionados a divergências entre a empresa de TV e a Rede Televisiva com relação ao controle criativo do processo de produção; e existe a preocupação com a criação de um ambiente de trabalho benigno para seus trabalhadores.

\section{Procedimentos Metodológicos}

As pesquisas sobre liderança têm sido tradicionalmente realizadas com abordagem quantitativa, onde se busca compreender a relação das variáveis de liderança com medidas de resultados (Bryman, 1998). Bryman (2011) destaca resultados de pesquisas realizadas em periódicos de liderança, negócios e gestão, onde predominou a preferência dos pesquisadores pela abordagem quantitativa.

No entanto, a ênfase da Abordagem da Nova Liderança que trata o líder como um gestor de significados exige uma compreensão mais aprofundada do contexto e uma sondagem mais detalhada junto aos pesquisados sobre os objetivos e impactos envolvidos, o que é proporcionado pela abordagem qualitativa (Bryman, 1998).

Pontua Bryman (1998) que apesar das pesquisas quantitativa e qualitativa serem diferentes abordagens, elas podem ser combinadas. A pesquisa qualitativa permite que se faça uma abordagem da liderança pela visão dos líderes e liderados, e a visualização dos aspectos do contexto que afetam a atuação das lideranças.

Lewis e Grimes (2007) também defendem o uso da metatriangulação como estratégia que faz uso da diversidade paradigmática para realçar facetas contraditórias, mas interligadas, do fenômeno em estudo. Lewis e Grimes (2007) defendem que a aplicação dessa estratégia gera maiores insights e criatividade.

Com base nesses autores, no presente estudo foi utilizada abordagem da pesquisa multiparadigmática, que consiste na utilização empírica de lentes paradigmáticas diferentes para a coleta e análise de dados (Lewis e Grimes, 2007). A pesquisa é, portanto, qualitativa quanto à natureza, com uso de estratégias de investigação quantitativa e qualitativa.

Quanto aos fins, a pesquisa é descritiva, e quanto aos meios, foram realizados o estudo bibliográfico, documental e de campo. Com a pesquisa documental foram consultados documentos das empresas e informações adicionais em seus sítios respectivos. Na pesquisa de campo, o método adotado foi o estudo de casos múltiplos, com finalidade comparativa (Yin, 2003), sendo as unidades de análise as equipes de telejornalismo da TV Assembleia, TV Jangadeiro e TV O POVO.

Como instrumentos de coleta de dados, aplicou-se o questionário do modelo de Liderança Criativa de Rickards e Moger (2000), com os líderes e liderados das equipes de telejornalismo. O questionário TFI é composto por 12 variáveis a serem mensuradas: 1) plataforma de entendimento; 2) visão compartilhada; 3) clima; 4)resiliência; 5) idéias próprias; 6) ativação em rede; 7) aprendizado vindo da experiência; 8) produtividade; 9) criatividade; 10) gerenciamento do conhecimento; 11) liderança transacional; 12) liderança transformacional. Cada fator é medido por meio de três sentenças afirmativas, o que totaliza 36 . Uma variável dummy foi introduzida no questionário, referente à primeira sentença, apenas para focar a atenção do respondente, totalizando 37 itens.

Cada sentença é respondida obedecendo a uma escala likert de 5 pontos $(5=$ concorda fortemente; 4 =concorda; 3 =neutro; 2 =discorda; 1 =discorda fortemente). A maior ou menor presença dos sete fatores de equipes criativas coloca a equipe, segundo a escala de TFI, entre os valores de 0 a 5 pontos, contidos em 3 faixas: Vindos do Inferno (1 a 1,87), que não consegue atingir performance razoável; Equipe Padrão (1,88 a 3,10), que mantém uma performance dentro da expectativa; e Equipe dos Sonhos $(3,11$ a 5,00$)$, que demonstra manter excelente performance.

Como segunda etapa, foi realizada entrevista semi-estruturada com os dirigentes das TVs, para levantamento dos aspectos qualitativos, relativos ao contexto de cada empresa: características gerais da organização, estratégias de liderança transacional e transformacional adotadas, percepção dos gestores acerca do desempenho de suas equipes, poder e conflitos. As entrevistas tiveram duração máxima de 1 hora, sendo gravadas e posteriormente transcritas.

Na TV Assembleia foram entrevistados o Diretor da TV, a Chefe de Redação, e o Chefe dos Cinegrafistas. Na TV Jangadeiro, a entrevista abrangeu a Gerente de Jornalismo e o Chefe de Redação. A aplicação da entrevista na TV O POVO envolveu o Diretor de Operações da TV, e a editora-chefe. A aplicação do questionário TFI foi realizada com os mesmos dirigentes acima citados, incluindo-se para a TV O POVO, o Gerente de Operações e o Gerente Técnico. 
Para a análise dos dados de natureza quantitativa foi utilizada a regressão linear simples e múltipla, para a investigação da relação entre o estilo de liderança e os sete fatores derivados da ação direta do líder do modelo de Rickards e Moger (2000), assim como entre o estilo de liderança e os fatores de resultado.

Os dados qualitativos foram analisados com a técnica de análise de conteúdo temática. Para a realização da análise foi utilizado o procedimento indutivo, onde a análise dos dados possibilita estabelecer relações entre os resultados obtidos e as perspectivas teóricas que situam e orientam a investigação (Bardin, 2003). Os temas definidos para a análise de conteúdo foram: 1) características da organização; 2) desempenho das equipes; 3) estratégias de liderança transacional: recompensas contingentes, gestão por exceção ativa e passiva; 4) estratégias de liderança transformacional: motivação inspiradora; estimulação intelectual; influência idealizada; e consideração individualizada; 5) poder e conflitos.

Finalizando a análise dos dados, as informações foram trianguladas para discussão final dos objetivos do estudo, como orientado por Bryman (1998).

\section{Apresentação e Análise dos Dados}

\subsection{Perfil das Empresas Pesquisadas}

\subsubsection{TV Assembleia}

A TV Assembleia é uma TV independente estatal, fundada em 7 de abril de 2006. Integra o organograma da Assembleia Legislativa, como "Núcleo de Televisão", e é diretamente subordinada à sua Mesa Diretora (Assembleia Legislativa do Estado do Ceará [AL], 2012). A TV Assembleia foi criada com a intenção de dar maior visibilidade às ações do Legislativo, sendo os pronunciamentos da Assembleia Legislativa transmitidos ao vivo, e por meio da TV os deputados recebem o feedback dos eleitores. Levantou-se que a TV conta com 60 colaboradores, e possui 16 programas, entre eles dois telejornais, e o Repórter Assembleia. A TV Assembleia não faz uso de fontes de receita, sendo suas necessidades supridas com os recursos públicos da Assembleia Legislativa.

Para a população de 60 colaboradores da TV, o tamanho mínimo calculado para um nível de confiança de $90 \%$ e erro de $10 \%$, e desvio-padrão de 0,48 foi de 31 . O questionário TFI foi aplicado com todos os colaboradores da redação da TV, e foi obtido retorno com 44 colaboradores, sendo $88,6 \%$ liderados e $11,4 \%$ líderes.

A idade média dos líderes da TV Assembleia foi de 48 anos, enquanto a dos liderados foi de 35 anos. Na amostra dos liderados, predominou a faixa etária de 22 a 30 anos. Quanto ao sexo: $60 \%$ dos líderes são do sexo feminino e $40 \%$ do masculino; e $59 \%$ dos liderados são do sexo masculino e $41 \%$ do sexo feminino.

\subsubsection{TV Jangadeiro}

A TV Jangadeiro é uma emissora de TV aberta, comercial, que veicula informações regionais, nacionais e internacionais de interesse do público cearense. Oferece uma programação de informação e lazer, com 15 programas (Jangadeiro Online, 2012, a). Os programas de cunho jornalístico são: Giro das Ruas, Ceará Notícias, Jangadeiro Esporte Clube, Barra Pesada, Jornal Jangadeiro 1a Edição, Jornal Jangadeiro 2a Edição, e Primeiro Plano (Jangadeiro Online, 2012).

A TV Jangadeiro é regional, envolvendo cerca de 154 dos 184 municípios cearenses. Foi afiliada da rede televisiva SBT em 2011. Recentemente, se tornou afiliada da Rede Bandeirantes de Televisão, a partir de março de 2012 (Band, 2011). É uma empresa de pequeno porte, com 22 anos de existência, e 210 colaboradores.

Na TV Jangadeiro, a equipe de produção dos telejornais se concentra no setor de jornalismo da referida empresa, composto, em 2011, por 50 funcionários, todos graduados na área de jornalismo, sendo 12 líderes e 38 liderados.

Para a população de 50 colaboradores, o tamanho mínimo calculado para um nível de confiança de $90 \%$ e erro de $10 \%$, e desvio-padrão de 0,45 foi de 27 . O questionário TFI foi aplicado com todos do setor de jornalismo da TV, e foi obtido retorno de 38 pessoas, sendo 28,9\% líderes e $71,1 \%$ liderados. Entre os liderados predomina o sexo masculino (70,4\%), e entre os líderes $54,5 \%$ são do sexo feminino. A idade média dos liderados é de 28 anos, e a dos líderes é de 33 anos.

\subsubsection{TV O Povo}

A TV O POVO é uma televisão educativa, de fins não lucrativos, pertencente à Fundação Demócrito Rocha, e afiliada da TV Cultura. Inaugurada em 9 de julho de 2007, conta com 20 programas de produção própria. É uma empresa de pequeno porte, com um faturamento de 6 milhões, e que conta com fontes de renda como a de apoio cultural. Possui 104 funcionários, onde todas as gerências têm curso superior e/ou podem estar cursando pós-graduação. A programação da TV abrange 17 programas. Destes, sete são de cunho jornalístico: Stúdio News, Grande Debate, Coletiva, Jogo Político, Vertical S/A, É Gol, e Trem Bala. 
Os programas jornalísticos são planejados e executados pelos colaboradores do setor CJOP - Central de Jornalismo O POVO, em parceria com alguns membros dos setores: Gerência Técnica (Equipe Técnica), e Gerência de Operações (Produção executiva, Edição de Imagem e arte, Switcher e Master, equipe externa e motoristas). A CJOP conta com 14 colaboradores, o setor de Gerência Técnica conta com 5 colaboradores, e a de Gerência de operações com 44. Isso totaliza 63 pessoas envolvidas com os programas jornalísticos. A partir desse total, foi calculada a amostra mínima para um nível de confiança de $90 \%$, erro de 10\%, e desvio-padrão de 0,42, resultando na amostra mínima de 28 pesquisados.

O questionário TFI foi aplicado com todos os colaboradores envolvidos com os programas de cunho jornalístico, obtendo-se retorno da quantidade mínima calculada na amostra, sendo 5 líderes e 23 liderados. Na amostra pesquisada, $78,6 \%$ dos pesquisados são do sexo masculino. Destes, $18,2 \%$ são líderes e $81,8 \%$ são liderados. Entre os respondentes do sexo feminino há apenas um líder. A idade média dos liderados foi de 31 anos, e entre os líderes, de 38 anos. Com relação à idade, faixas etárias predominantes foram de 27 a 29 anos, e 30 a 38 anos. Destaca-se que $25 \%$ dos liderados se situaram na faixa etária de 18 a 26 anos.

\subsection{Desempenho Criativo das Equipes}

Os resultados do instrumento TFI apontaram que a equipe da TV Assembleia se autoavaliou como “Equipe dos sonhos" na classificação do modelo de Rickards e Moger (2000), alcançando média TFI de 3,72. Contudo, a análise qualitativa revelou que do Diretor da TV Assembleia considera que existe ainda um atrelamento dos jornalistas de sua equipe com o que é feito nas TVs Comerciais, explicando que eles não consideram, como gostaria, as peculiaridades da TV onde trabalham.

O diretor da TV Assembleia acredita que os jornalistas poderiam inovar muito mais se considerassem essa questão, de forma que não ficassem presos a um padrão quase que global de rotinas jornalísticas:

(...) eles poderiam se soltar mais, sair um pouco mais do comum do dia a dia. Então eu não acho que há uma criatividade maior. Só em mostrar o legislativo é uma criatividade, mas que já deixou de ser, pois em outros estados já se está fazendo isso. (...) Detalhar o fato, buscando assuntos relacionados, indo atrás do que a legislação diz, etc, não é ser criativo, pois isso as demais TV de cunho legislativo também fazem (Entrevista Diretor da TV Assembleia).

O diretor da TV acredita que uma das barreiras ao desempenho criativo das equipes é a própria formação do jornalista, que já vem com um padrão de trabalho definido, e que falta à sua equipe uma maior ousadia para que não se prenda tanto a rotina. Outra barreira são as limitações técnicas, de estrutura física e de aquisição de material, trazidas pelo fato da TV depender de recursos públicos.

A chefe de redação aponta a própria variação da mesa diretora como um fator negativo para o desempenho da equipe, que faz variar também as diretrizes que deve seguir. Sobre o desempenho atual de sua equipe, a chefe de redação afirmou que existem na equipe pessoas que são proativas, e outras que não possuem muito comprometimento. Considera a equipe criativa, mas enfatiza que sempre é possível aperfeiçoar mais o trabalho, por isso acompanha de perto o desempenho da equipe, cobrando melhores resultados. $A$ respeito das rotinas jornalísticas, a chefe de redação afirma que a rotina do dia a dia melhora o resultado final do trabalho, à medida que o indivíduo se aperfeiçoa no processo, e não se acomoda.

A Equipe da TV Jangadeiro também se autoavaliou como "equipe dos sonhos" por meio do instrumento TFI do modelo de Rickards e Moger (2000), alcançando média TFI de 3,99. A gerente de jornalismo da TV considera que a equipe tem razão em se autoavaliar positivamente, pelo grande esforço que a empresa requer em termos de atender a um maior número de horas de programação (muito mais produção local veiculada na emissora), e de conseguir audiência, se comparado a outras TVs locais, vinculadas a redes de TV distintas, que possuem uma quantidade de horas de programação menor, e audiência mais facilitada por essas redes.

Afirma a gerente que a audiência da TV Jangadeiro depende muito mais de seu esforço próprio, do que do aproveitamento da audiência da rede à qual está vinculada. A equipe tem superado bem todos os desafios, conseguindo que programas da TV, se mantenham em liderança ou vice-liderança de audiência local, competindo muito bem, inclusive com a programação das emissoras líderes de audiência nacional, ao conquistar seu público alvo com sua programação local.

Indagada sobre as barreiras ao desempenho criativo da equipe, a gerente de jornalismo preferiu tratá-las como desafios. A gerente apontou a própria infraestrutura da empresa como um desafio, por ser pequena, se comparada a outras TVs com estruturas melhores. Outro desafio era o fato da Rede SBT, a qual a TV Jangadeiro estava vinculada, trabalhar mais com entretenimento do que com jornalismo, que é o enfoque maior da organização.

Sobre a criatividade na mídia televisiva, a gerente de jornalismo da TV Jangadeiro afirma que ser criativo é enfatizar o que é importante para a comunidade local, é fazer uso das mídias sociais para promover maior interação com os telespectadores dos programas, é deixar o telespectador com a impressão de que estão fazendo o programa junto com a TV, é ser desse modo uma TV pioneira, buscando sempre estar um passo a frente das demais emissoras. 
A equipe da TV O POVO se autoavaliou como "Equipe dos sonhos", alcançando média TFI de 4,08, maior média de todas as TVs pesquisadas. Sobre sua equipe, na entrevista, o Diretor de Operações da TV O POVO apontou as seguintes qualidades: trabalha em harmonia, sem clima de competição, há comprometimento com os resultados, e seus membros são pessoas talentosas e motivadas. Ele destaca como carências da equipe, o fato de ser composta por pessoas muito jovens, faltando, por isso, um maior amadurecimento do grupo:

A equipe vai superar minhas expectativas quando ela precisar cada vez menos de mim, de forma que eu possa me restringir apenas ao um trabalho de motivador, de ficar mais livre para gerenciar os resultados (...) quanto mais desnecessário eu for, em processos operacionais, mais vou poder me dedicar no cumprimento de um papel mais estratégico e de motivação, o que vai ser melhor para a equipe (Entrevista Diretor de Operações da TV O Povo).

A editora-chefe da TV O POVO afirma que:

O desempenho da equipe é razoável, falta um pouco de maturidade, tem altos e baixos, tem momentos muito bons, mas também há momentos muito ruins, por causa dessa falta de maturidade, de serem mais responsáveis e proativos, de fazerem um capricho final, de serem curiosos, de ter atenção, (...),considerar que o seu papel é muito importante para que o produto final seja bom. Então busco incentivá-los nessa autonomia, de cada um estar consciente do seu papel, de estar analisando suas tarefas da melhor forma possível, e todo processo vai ser encaminhado sem problemas, sem contratempos (Entrevista Editora-chefe da TV O Povo).

Sobre as barreiras ao desempenho criativo, o diretor da TV O POVO destaca que um dos grandes desafios que tem enfrentado é a promoção da motivação, manter as pessoas confiantes, estimuladas, animadas para dar ideias novas, ou seja, tirar as pessoas da rotina burocrática, em busca de uma inconformidade saudável, de forma que as pessoas estejam sempre predispostas a inovar.

Acerca do que consiste um telejornal criativo, o Diretor respondeu:

(...) Assim, ser criativo e inovador em telejornalismo é fugir dos clichês, é usar menos fórmulas e mais material investigativo, exclusivo, é aprimorar sempre a clareza, a precisão, apresentar textos e imagens envolventes, sem serem apelativos, é buscar novas abordagens de temas recorrentes, é aguçar o olhar por novos ângulos, (...), é surpreender os telespectadores e prender sua atenção, sempre contribuindo para o desenvolvimento econômico, educacional e cultural de toda a sociedade que sintoniza a TV O POVO (Entrevista Diretor de Operações da TV O Povo).

Ainda sobre a criatividade do telejornal, o Diretor da TV O POVO afirma que é um erro acreditar que normas de procedimento ou rotinas bem traçadas, inibam a criatividade. De acordo com o aprendizado por ele obtido em um MBA de Gestão Empresarial, ocorre justamente o contrário:

(...) quanto mais o dia-a-dia, o "feijão com arroz" for feito sem atropelos e com qualidade, mais criativos e inovadores todos os colaboradores poderão ser naquilo que verdadeiramente gera valor. Quero que toda a minha equipe seja o mais criativa e inovadora possível, e acredito que isso fica mais fácil de florescer num terreno bem adubado pela conformidade (Entrevista Diretor de Operações da TV O Povo).

\subsection{Relação entre Estilo de Liderança e Fatores de Liderança Criativa}

Para responder sobre qual estilo de liderança está mais relacionado com a performance criativa da equipe utilizou-se a análise de regressão linear múltipla, com uso do método enter. Para viabilizar essa análise, os sete fatores de liderança criativa, que derivam da ação direta do líder e de suas relações com os membros da equipe, foram transformados na variável "Fatores Benignos", variável dependente da regressão, obtido pelo cálculo do valor médio dos sete fatores, para o grupo de 110 pesquisados (líderes e liderados). A criação dessa variável foi necessária, pela existência de forte correlação entre os fatores de liderança criativa, que geraria problema de multicolinariedade na análise de regressão.

Para cada empresa de TV, os valores médios obtidos para a variável "Fatores benignos" foram: 4,06 para a TV O Povo, 3,90 para a TV Jangadeiro, e 3,57 para a TV Assembleia, demonstrando que a equipe da TV O Povo foi a que melhor considerou a atuação das lideranças na constituição dos fatores benignos necessários ao melhor desempenho da equipe.

Sendo encontrada forte correlação entre as variáveis "Liderança Transformacional" e "Liderança Transacional", essas variáveis independentes foram aplicadas separadamente na regressão múltipla, juntamente com duas variáveis dummy, a primeira referente a TV O Povo e a segunda à TV Jangadeiro, considerando-se a TV Assembleia como base da análise.

Foram respeitadas as hipóteses da regressão múltipla, tanto no modelo com a variável previsora "Liderança Transformacional", como no modelo com a variável previsora "Liderança Transacional". A hipótese da multicolinearidade, evitando-se a aplicação de variáveis previsoras com forte correlação linear; a hipótese da homocedasticidade, sendo realizado o Teste de Levene considerando os três grupos de TVs, onde foi constatada significância superior a 5\%, confirmando a hipótese nula de que as variâncias populacionais são homogêneas; a hipótese dos erros independentes também foi verificada por meio do teste de Durbin-Watson, que ficou próximo de 2 (Tabelas 1 e 2); e a hipótese da normalidade dos erros distribuídos, pois constatou-se pelo diagrama P-P 
(Figura 1) que os pontos estão bem próximos da linha que representa a distribuição normal, não sendo visualizado um grande afastamento da normalidade.

Observou-se que o conjunto de variáveis do primeiro modelo (liderança transformacional, e variáveis dummy TV O Povo e TV Jangadeiro) explica cerca de $60 \%$ da variação da variável dependente “Fatores Benignos", apresentando o modelo significância estatística (Tabelas 1 e 3).

Por sua vez, o segundo modelo, com a variável liderança transacional como preditora, juntamente com as variáveis dummy TV O Povo e TV Jangadeiro, explica $40 \%$ da variação da variável dependente "Fatores Benignos", apresentando o modelo significância estatística (Tabelas 2 e 4).

$\mathrm{O}$ valor de $\mathrm{F}$ do primeiro modelo (Tabela 3) é mais do que o dobro do valor de $\mathrm{F}$ do segundo modelo (Tabela 4), reforçando a constatação de que o modelo com a liderança transformacional tem um poder explicativo melhor sobre a variação da variável "Fatores Benignos", do que o modelo com a liderança transacional.

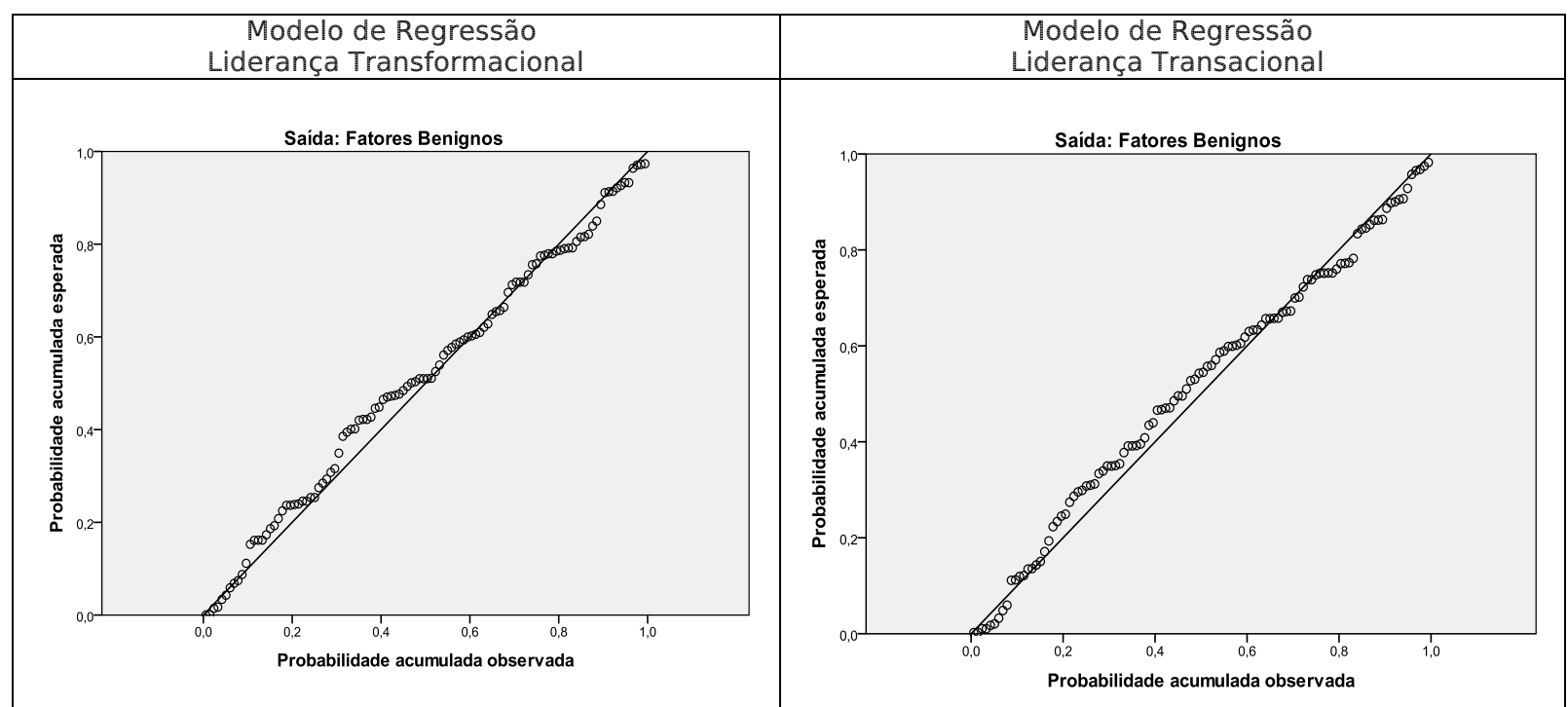

Figura 1. Diagrama P-P dos resíduos normalmente distribuídos dos modelos de regressão Fonte: Resultados da pesquisa

Tabela 1:

Teste de Durbin-Watson, Modelo de Regressão Liderança Transformacional

\begin{tabular}{|c|c|c|c|c|c|c|c|c|c|c|}
\hline \multirow[b]{2}{*}{ Modelo } & \multirow[b]{2}{*}{$\mathrm{R}$} & \multirow[b]{2}{*}{$\begin{array}{c}\text { R } \\
\text { Quadrado }\end{array}$} & \multirow[b]{2}{*}{$\begin{array}{c}\text { R } \\
\text { Quadrad } \\
\text { o } \\
\text { Ajustado }\end{array}$} & \multirow[b]{2}{*}{$\begin{array}{l}\text { Erro } \\
\text { padrão da } \\
\text { Estimativa }\end{array}$} & \multicolumn{5}{|c|}{ Estatísticas de Mudanças } & \multirow[b]{2}{*}{$\begin{array}{l}\text { Durbin- } \\
\text { Watson }\end{array}$} \\
\hline & & & & & $\begin{array}{l}\text { Mudança no } \\
\text { R Quadrado }\end{array}$ & $\begin{array}{c}\text { Mudança } \\
\text { no F }\end{array}$ & $\mathrm{gll}$ & $\mathrm{g} / 2$ & $\begin{array}{c}\text { Mudança } \\
\text { na } \\
\text { Significânc } \\
\text { ia do F }\end{array}$ & \\
\hline 1 & 777 & 603 &, 592 & ,34482 & 603 & 53,757 & 3 & 106 &, 000 & 2,085 \\
\hline
\end{tabular}

Nota. Preditores: (Constante), Liderança Transformacional; Variáveis Dummy TV_POVO e TV」JANG; Variável dependente: Fatores benignos.

Fonte: Resultados da Pesquisa.

Tabela 2:

Teste de Durbin-Watson, Modelo de Regressão Liderança Transacional

\begin{tabular}{|c|c|c|c|c|c|c|c|c|c|c|}
\hline \multirow[b]{2}{*}{ Modelo } & \multirow[b]{2}{*}{$R$} & \multirow[b]{2}{*}{$\begin{array}{c}\text { R } \\
\text { Quadrado }\end{array}$} & \multirow{2}{*}{$\begin{array}{c}\text { R } \\
\text { Quadrad } \\
\text { o } \\
\text { Ajustado }\end{array}$} & \multirow[b]{2}{*}{$\begin{array}{c}\text { Erro } \\
\text { padrão da } \\
\text { Estimativa }\end{array}$} & \multicolumn{5}{|c|}{ Estatísticas de Mudanças } & \multirow[b]{2}{*}{$\begin{array}{l}\text { Durbin- } \\
\text { Watson }\end{array}$} \\
\hline & & & & & $\begin{array}{l}\text { Mudança no } \\
\text { R Quadrado }\end{array}$ & $\begin{array}{c}\text { Mudança } \\
\text { no F }\end{array}$ & gl1 & $\mathrm{gl} / 2$ & $\begin{array}{l}\text { Mudança na } \\
\text { Significância } \\
\end{array}$ & \\
\hline 1 &, 640 & ,409 &, 393 & ,42077 & ,409 & 24,498 & 3 & 106 &, 000 & 2,316 \\
\hline
\end{tabular}

Nota. Preditores: (Constante), Liderança Transacional; Variáveis Dummy TV_POVO e TV_ANG. Variável dependente: Fatores benignos.

Fonte: Resultados da Pesquisa

Tabela 3:

Análise de Variância, Modelo de Regressão Liderança Transformacional

\begin{tabular}{|c|c|c|c|c|c|c|}
\hline Modelo & & Soma dos Quadrados & $\mathrm{gl}$ & Média dos quadrados & $\mathrm{F}$ & Sig. \\
\hline \multirow{3}{*}{1} & Regressão & 19,176 & 3 & 6,392 & 53,757 &, 000 \\
\hline & Resíduo & 12,604 & 106 & ,119 & & \\
\hline & Total & 31,780 & 109 & & & \\
\hline
\end{tabular}

Nota. Preditores: (Constante), Liderança Transformacional; Variáveis Dummy TV_POVO e TV」ANG. Variável dependente: Fatores benignos.

Fonte: Resultados da Pesquisa. 
As estimativas dos valores beta (Tabelas 05 e 06) indicam a contribuição individual de cada previsor para o modelo. Constata-se que para ambos os modelos os valores de b são positivos, o que significa que há um relacionamento positivo e significativo a nível de $5 \%$ entre os previsores e a saída. À medida que os valores de liderança transformacional e transacional aumentam, aumentam os valores da variável fatores benignos, destacando-se a liderança transformacional com o maior valor de resultado gerado a cada aumento de uma unidade em sua média.

Tabela 4:

Análise de Variância, Modelo de Regressão Liderança Transacional

\begin{tabular}{|c|c|c|c|c|c|c|}
\hline & Modelo & Soma dos Quadrados & $g \mid$ & Média dos quadrados & $\mathrm{F}$ & Sig. \\
\hline \multirow{3}{*}{2} & Regressão & 13,012 & 3 & 4,337 & 24,498 &, 000 \\
\hline & Resíduo & 18,767 & 106 &, 177 & & \\
\hline & Total & 31,780 & 109 & & & \\
\hline
\end{tabular}

Nota. Preditores: (Constante), Liderança Transacional; Variáveis Dummy TV_POVO e TV_ANG; Variável dependente: Fatores benignos.

Fonte: Resultados da Pesquisa.

Tabela 5:

Coeficientes do Modelo de Regressão, Modelo Liderança Transformacional

\begin{tabular}{|c|c|c|c|c|c|c|c|c|c|c|}
\hline & \multirow[b]{2}{*}{ Modelo } & \multicolumn{2}{|c|}{$\begin{array}{c}\text { Coeficientes não- } \\
\text { padronizados }\end{array}$} & \multirow{2}{*}{$\begin{array}{c}\text { Coeficientes } \\
\text { padronizado } \\
\text { s } \\
\text { Beta }\end{array}$} & \multirow[b]{2}{*}{$\mathrm{t}$} & \multirow[b]{2}{*}{ Sig. } & \multicolumn{2}{|c|}{$\begin{array}{c}\text { Intervalo de } \\
\text { confiança de } 95 \% \\
\text { para B }\end{array}$} & \multicolumn{2}{|c|}{$\begin{array}{c}\text { Estatísticas de } \\
\text { Colinearidade }\end{array}$} \\
\hline & & B & $\begin{array}{c}\text { Erro } \\
\text { Padrão }\end{array}$ & & & & $\begin{array}{l}\text { Limite } \\
\text { Inferior }\end{array}$ & $\begin{array}{c}\text { Limite } \\
\text { Superior }\end{array}$ & $\begin{array}{c}\text { Tolerânc } \\
\text { ia }\end{array}$ & VIF \\
\hline \multirow[t]{4}{*}{1} & (Constant) & 1,719 &, 175 & & $\begin{array}{c}9,82 \\
2\end{array}$ &, 000 & 1,372 & 2,066 & & \\
\hline & $\begin{array}{l}\text { Liderança } \\
\text { Transformacional } \\
\text { (L_TRF) }\end{array}$ & ,478 &, 043 & ,692 & $\begin{array}{c}11,1 \\
05\end{array}$ &, 000 & ,393 &, 564 & 964 & $\begin{array}{c}1,03 \\
8\end{array}$ \\
\hline & TV JANG & 183 & 077 & ,162 & $\begin{array}{c}2,35 \\
8\end{array}$ & ,020 & ,029 & ,336 & ,796 & $\begin{array}{c}1,25 \\
6\end{array}$ \\
\hline & TV_POVO &, 341 & ,084 & ,277 & $\begin{array}{c}4,04 \\
7\end{array}$ &, 000 &, 174 & ,509 & ,801 & $\begin{array}{c}1,24 \\
9\end{array}$ \\
\hline
\end{tabular}

Nota. Preditores: (Constante), Liderança Transformacional; Variáveis Dummy TV_POVO e TV」ANG. Variável Dependente: Fatores Benignos

Fonte: Resultados da Pesquisa

Com relação às variáveis dummy, constatou-se que, em ambos os modelos de regressão, o valor da variável fatores benignos aumenta significativamente mais com a equipe da TV O Povo e TV Jangadeiro, do que com a TV Assembleia. A TV O Povo se destaca pelo maior aumento gerado nos fatores benignos.

Tabela 6:

Coeficientes do Modelo de Regressão, Modelo Liderança Transacional

\begin{tabular}{|c|c|c|c|c|c|c|c|c|c|c|}
\hline & \multirow[b]{2}{*}{ Modelo } & \multicolumn{2}{|c|}{$\begin{array}{l}\text { Coeficientes } \\
\text { não- } \\
\text { padronizados }\end{array}$} & \multirow{2}{*}{$\begin{array}{c}\begin{array}{c}\text { Coeficientes } \\
\text { padronizado } \\
\text { s }\end{array} \\
\text { Beta }\end{array}$} & \multirow[b]{2}{*}{ T } & \multirow[b]{2}{*}{ Sig. } & \multicolumn{2}{|c|}{$\begin{array}{c}\text { Intervalo de } \\
\text { confiança de } 95 \% \\
\text { para B }\end{array}$} & \multicolumn{2}{|c|}{$\begin{array}{l}\text { Estatísticas de } \\
\text { Colinearidade }\end{array}$} \\
\hline & & B & $\begin{array}{l}\text { Erro } \\
\text { Padrão }\end{array}$ & & & & $\begin{array}{l}\text { Limite } \\
\text { Inferior }\end{array}$ & $\begin{array}{l}\text { Limite } \\
\text { Superior }\end{array}$ & Tolerância & VIF \\
\hline \multirow{4}{*}{2} & (Constant) & 2,103 &, 222 & & $\begin{array}{c}9,49 \\
1\end{array}$ &, 000 & 1,664 & 2,543 & & \\
\hline & $\begin{array}{c}\text { Liderança } \\
\text { Transacional } \\
\text { (L TRA) }\end{array}$ &, 380 &, 055 & .518 & $\begin{array}{c}6,92 \\
9\end{array}$ &, 000 &, 271 & ,489 & ,997 & 1,004 \\
\hline & TV」ANG & ,297 &, 093 &, 262 & $\begin{array}{c}3,17 \\
9\end{array}$ & ,002 &, 112 & ,482 & ,818 & 1,223 \\
\hline & TV_POVO & ,490 & ,102 & ,397 & 4,81 &, 000 & ,289 & ,692 & 820 & 1,220 \\
\hline
\end{tabular}

Nota. Preditores: (Constante), Liderança Transacional; Variáveis Dummy TV_POVO e TV」ANG. Variável Dependente: Fatores Benignos

Fonte: Resultados da Pesquisa

\subsection{Relação entre Estilo de Liderança e Fatores de Resultado da Equipe}

Para responder sobre qual estilo de liderança está mais relacionado com as variáveis de resultado das equipes, foi utilizada a análise de regressão linear simples, considerando as informações coletadas com o grupo de 110 pesquisados das três empresas de TV.

Os três fatores de resultados (produtividade, criatividade e gerenciamento do conhecimento) foram transformados na variável "Resultado da Equipe" para a realização da análise, somando-se os valores das três variáveis e dividindo por três.

Os valores médios obtidos para a variável "Resultado da Equipe", para cada empresa de TV, foram: 4,2 para a TV O Povo, 4,1 para a TV Jangadeiro, e 4,0 para a TV Assembleia, demonstrando que não há diferença 
significativa entre as equipes com relação ao resultado alcançado, o que dispensou o uso de uma regressão múltipla com as variáveis dummy relativas a cada TV, como feito no tópico anterior.

Pela mesma motivação apontada no tópico anterior, serão analisados dois modelos de regressão, um com o previsor "Liderança Transformacional" e outro com o previsor "Liderança Transacional", com a finalidade de investigar o estilo de liderança que provoca maior aumento no valor da variável "Resultado da Equipe".

Foram respeitadas as hipóteses da regressão, em ambos os modelos testados. A hipótese da homocedasticidade, sendo realizado o Teste de Levene considerando os três grupos de TVs, onde foi constatada significância superior a 5\%, confirmando a hipótese nula de que as variâncias populacionais são homogêneas; a hipótese dos erros independentes também foi verificada por meio do teste de Durbin-Watson, que ficou próximo de 2 (Tabelas 7 e 8); e a hipótese da normalidade dos erros distribuídos, pois constatou-se pelo diagrama P-P (Figura 2) que os pontos estão bem próximos da linha que representa a distribuição normal, não sendo visualizado um grande afastamento da normalidade.

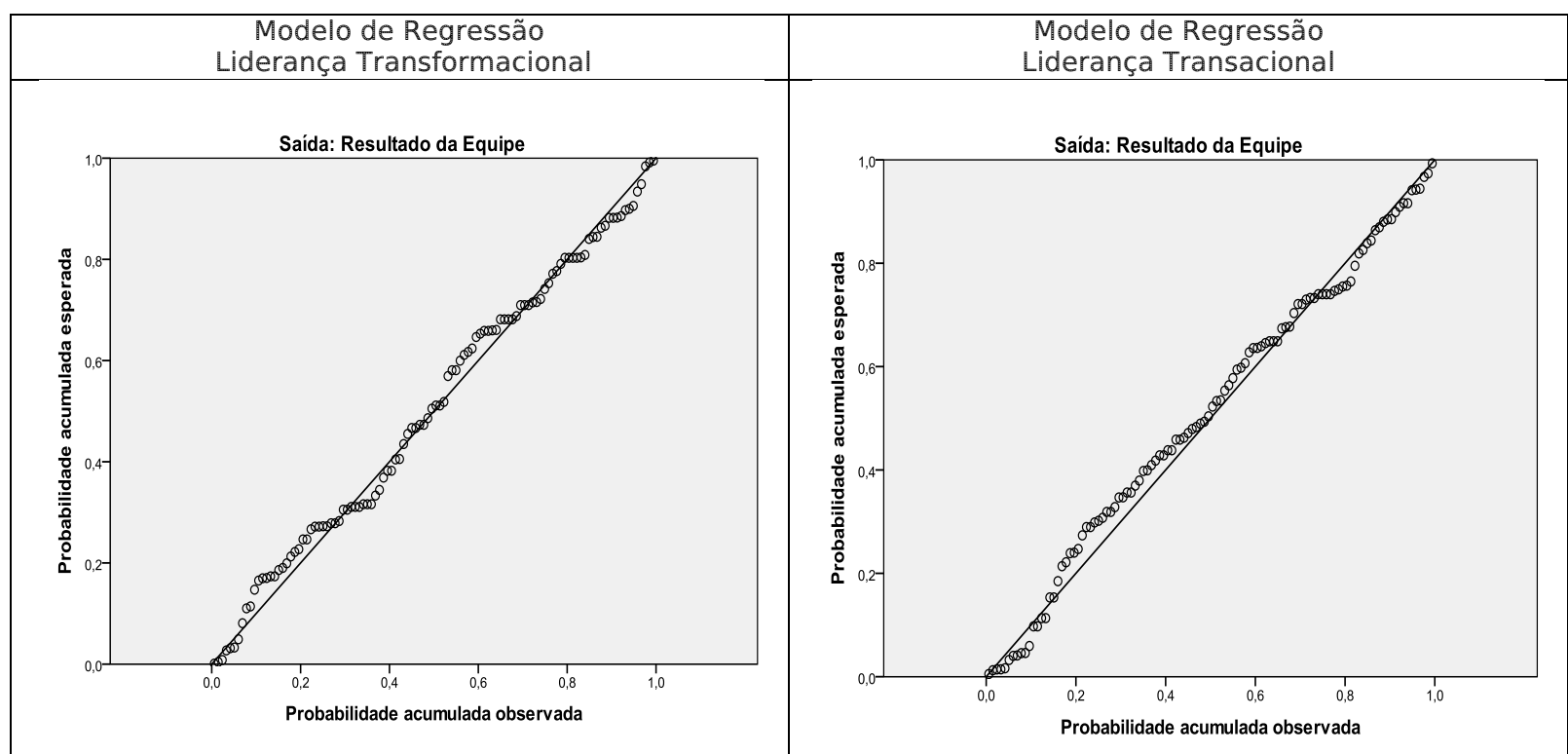

Figura 2. Diagrama P-P dos resíduos normalmente distribuídos dos modelos de regressão

Fonte: Resultados da pesquisa

Os resultados revelam que a Liderança Transformacional explica 43,5\% da variação do fator “Resultado da Equipe", enquanto a Liderança Transacional só explica 25,5\% da variação (Tabelas 7 e 8 ).

Analisando o coeficiente beta de ambas as regressões (Tabelas 9 e 10), verifica-se que os valores são positivos, significando que há um relacionamento positivo e significativo a nível de $5 \%$ entre os previsores de liderança e a saída. Os valores dos previsores de liderança aumentam, assim como aumentam os valores da variável "resultado da equipe". A liderança transformacional se destaca com o maior valor do coeficiente beta. Dessa forma, em comparação com a liderança transacional, a liderança transformacional gera um maior aumento do resultado da equipe, a cada aumento de uma 1 unidade de sua média.

Tabela 7:

Teste de Durbin-Watson, Modelo de Regressão Liderança Transformacional

\begin{tabular}{|c|c|c|c|c|c|c|c|c|c|c|}
\hline \multirow[b]{2}{*}{ Modelo } & \multirow[b]{2}{*}{$\mathrm{R}$} & \multirow[b]{2}{*}{$\begin{array}{c}\mathrm{R} \\
\text { Quadrado }\end{array}$} & \multirow{2}{*}{$\begin{array}{c}\text { R } \\
\text { Quadrad } \\
\text { o } \\
\text { Ajustado }\end{array}$} & \multirow[b]{2}{*}{$\begin{array}{c}\text { Erro } \\
\text { padrão da } \\
\text { Estimativa }\end{array}$} & \multicolumn{5}{|c|}{ Estatísticas de Mudanças } & \multirow[b]{2}{*}{$\begin{array}{l}\text { Durbin- } \\
\text { Watson }\end{array}$} \\
\hline & & & & & $\begin{array}{l}\text { Mudança no } \\
\text { R Quadrado }\end{array}$ & $\begin{array}{c}\text { Mudança } \\
\text { no F }\end{array}$ & gl1 & $g / 2$ & $\begin{array}{c}\text { Mudança na } \\
\text { Significância } \\
\text { do F }\end{array}$ & \\
\hline 1 & ,660 &, 435 &, 430 & ,40865 & ,435 & 83,170 & 1 & $\begin{array}{c}10 \\
8\end{array}$ & ,000 & 2,13 \\
\hline
\end{tabular}

Nota. Preditores: (Constante), Liderança Transformacional; Variável dependente: Resultado da Equipe.

Fonte: Resultados da Pesquisa

Tabela 8:

Teste de Durbin-Watson, Modelo de Regressão Liderança Transacional

\begin{tabular}{|c|c|c|c|c|c|c|c|c|c|c|}
\hline \multirow[b]{2}{*}{ Modelo } & \multirow[b]{2}{*}{$\mathrm{R}$} & \multirow[b]{2}{*}{$\begin{array}{c}\mathrm{R} \\
\text { Quadrado }\end{array}$} & \multirow{2}{*}{$\begin{array}{c}\text { R } \\
\text { Quadrad } \\
\text { o } \\
\text { Ajustado }\end{array}$} & \multirow[b]{2}{*}{$\begin{array}{c}\text { Erro } \\
\text { padrão da } \\
\text { Estimativa }\end{array}$} & \multicolumn{5}{|c|}{ Estatísticas de Mudanças } & \multirow[b]{2}{*}{$\begin{array}{l}\text { Durbin- } \\
\text { Watson }\end{array}$} \\
\hline & & & & & $\begin{array}{l}\text { Mudança no } \\
\text { R Quadrado }\end{array}$ & $\begin{array}{c}\text { Mudança } \\
\text { no } F\end{array}$ & gll & $g \mid 2$ & $\begin{array}{c}\text { Mudança na } \\
\text { Significância } \\
\text { do F }\end{array}$ & \\
\hline 1 &, 505 &, 255 &, 248 & ,46934 & ,255 & 36,922 & 1 & $\begin{array}{c}10 \\
8\end{array}$ & ,000 & 2,21 \\
\hline
\end{tabular}

Nota. Preditores: (Constante), Liderança Transacional; Variável dependente: Resultado da Equipe.

Fonte: Resultados da Pesquisa 
Vivianne Pereira Salas Roldan, Augusto Cézar de Aquino Cabral, Maria Naiula Monteiro Pessoa, Rodrigo Bandeira-de-Mello, Sandra Maria dos Santos, Tereza Cristina Batista de Lima

Tabela 9:

Coeficiente da Regressão Simples, Modelo Liderança Transformacional

\begin{tabular}{|c|c|c|c|c|c|c|c|}
\hline \multirow[b]{2}{*}{ Modelo } & $\begin{array}{r}\text { Coeficie } \\
\text { padro }\end{array}$ & $\begin{array}{l}\text { es não- } \\
\text { zados }\end{array}$ & \multirow[t]{2}{*}{$\begin{array}{c}\text { Coeficientes } \\
\text { padronizado } \\
\mathrm{s} \\
\end{array}$} & \multirow[b]{2}{*}{ T } & \multirow[b]{2}{*}{ Sig. } & \multicolumn{2}{|c|}{ Estatísticas de Colinearidade } \\
\hline & $B$ & $\begin{array}{c}\text { Erro } \\
\text { Padrão }\end{array}$ & & & & Tolerância & VIF \\
\hline (Constant) & 2,225 &, 207 & & $\begin{array}{l}10 \\
738\end{array}$ &, 000 & & \\
\hline $\begin{array}{c}\text { Liderança Transformacional } \\
\text { (L TRF) }\end{array}$ & ,457 & ,050 & ,660 & 9,12 &, 000 & 1,00 & 1,00 \\
\hline
\end{tabular}

Nota. Preditores: (Constante), Liderança Transformacional. Variável Dependente: Resultado da Equipe

Fonte: Resultados da Pesquisa

Tabela 10:

Coeficiente da Regressão Simples, Modelo Liderança Transacional

\begin{tabular}{|c|c|c|c|c|c|c|c|}
\hline \multirow[b]{2}{*}{ Modelo } & \multicolumn{2}{|c|}{$\begin{array}{c}\text { Coeficientes não- } \\
\text { padronizados }\end{array}$} & \multirow{2}{*}{$\begin{array}{c}\begin{array}{c}\text { Coeficientes } \\
\text { padronizado } \\
\text { s }\end{array} \\
\text { Beta } \\
\end{array}$} & \multirow[b]{2}{*}{$\mathrm{T}$} & \multirow[b]{2}{*}{ Sig. } & \multicolumn{2}{|c|}{ Estatísticas de Colinearidade } \\
\hline & B & $\begin{array}{c}\text { Erro } \\
\text { Padrão }\end{array}$ & & & & Tolerância & VIF \\
\hline (Constant) & 2,635 &, 242 & & 10,879 &, 000 & & \\
\hline $\begin{array}{c}\text { Liderança } \\
\text { Transacional(L_TRA) }\end{array}$ & ,371 & 061 &, 505 & 6,08 &, 000 & 1,00 & 1,00 \\
\hline
\end{tabular}

Nota. Preditores: (Constante), Liderança Transacional. Variável Dependente: Resultado da Equipe

Fonte: Resultados da Pesquisa

\subsection{Estratégias Utilizadas pelas Lideranças}

A realização de reuniões é a principal estratégia utilizada pelas lideranças das TVs para transmissão da linha editorial a ser seguida pela equipe, a definição do desempenho que se deseja alcançar e o seu acompanhamento. Há um elevado controle sobre o conteúdo que será levado ao ar para o telespectador, em todas as TVs. De acordo com Becker et al. (2011) a preocupação com a gestão do risco criativo e operacional é um fator crítico para as empresas de televisão. Nas TVs pesquisadas, os erros não são tolerados, gerando punições:

(...) é considerada uma falha grave o fato de se publicar algo sem consultar a fonte, ou sem ter a certeza de sua veracidade, pois pode sujeitar a empresa a riscos de responder a processos judiciais. Principalmente quanto a questões político-econômicas é arriscado publicar algo sem investigar a veracidade da fonte. Caso aconteça esse tipo de erro, se não trouxer consequências muito graves para a empresa, o funcionário recebe apenas uma advertência pessoal. Logo em seguida, é enviado um email, alertando de uma forma geral para todos, acerca desse cuidado necessário. Em casos de grande prejuízo para a empresa, o funcionário é demitido (Entrevista Gerente de Jornalismo da TV Jangadeiro).

(...) São tomadas atitudes no mesmo peso das consequências trazidas para a Assembleia. O erro do dia a dia é chamado atenção, mas não abala tanto a equipe. (...) um cinegrafista não estava presente no horário estipulado para ele cobrir a sessão plenária, e o presidente da sessão quis começar sem esperar o cinegrafista, o que foi considerado um erro grave. A direção conversou com o cinegrafista e deu uma suspensão como sanção (...). A ocorrência do erro e (...) punição é comunicada para toda a equipe (Entrevista Diretor da TV Assembleia).

No contexto das organizações televisivas, a realização de reuniões pode ser compreendida como um processo que atende a gestão do risco criativo e operacional, e caracteriza um aspecto da liderança transacional quanto à gestão por exceção ativa, quando o líder realiza uma supervisão ativa do desempenho da equipe, buscando impedir as falhas antes que elas ocorram. A aplicação de sanções após a ocorrência dos erros, corresponde ao aspecto da liderança transacional, denominado gestão por exceção passiva (Bass \& Avolio, 1994).

As lideranças nas TVs não definem um desempenho padrão esperado que se deseja alcançar, de maneira formalizada, para alimentar o processo de gestão por exceção ativa. Isso pode ser explicado pelo fato das organizações analisadas não adotarem ainda o planejamento estratégico. A diretriz padrão que as equipes devem seguir é a linha editorial da empresa, repassada verbalmente na TV Jangadeiro e TV Assembleia, e definida por escrito na TV O POVO.

Explica o diretor da TV Assembleia, que a linha editorial da TV é determinada pela Mesa Diretora da Assembleia Legislativa. A linha editorial vai variar conforme a mesa diretora atuante, tendo cada uma delas sua identidade. Ainda sobre o planejamento estratégico, o Diretor e a Chefe de redação da TV Assembleia afirmam que o planejamento estratégico da Assembleia Legislativa, que se estende a TV, está em desenvolvimento, com apoio da Fundação Dom Cabral.

O desempenho dos colaboradores é avaliado diariamente nas reuniões, e no próprio decorrer das atividades. Na TV Jangadeiro, a produtividade da equipe é avaliada pela meta a ser alcançada em termos de audiência. Ainda como estratégia de liderança transacional, de gestão por exceção ativa, a direção da TV O 
POVO busca manualizar alguns procedimentos, criando o POPS - Procedimento operacional padrão, buscando a sinergia a e proatividade. Nela os papéis e responsabilidades dos colaboradores são definidos por escrito.

O uso de recompensas contingentes é um dos fatores que caracteriza a liderança transacional (Bass \& Avolio, 1994). Os dirigentes das TVs afirmam que o comportamento criativo é reconhecido e premiado no corpo funcional por meio de incentivos não financeiros, dentre os quais se destacou em todas as TVs a possibilidade de ascensão de carreira e realização de treinamentos.

Na TV Jangadeiro e na TV Assembleia foi constatado que a recompensa é prometida de forma explícita para o desempenho criativo, o que pode elevar a motivação dos colaboradores para a criatividade (Eisenberger \& Shanock, 2003). Estratégias relacionadas ao estilo de liderança transformacional também foram identificadas nos depoimentos dos gestores, quanto à: motivação inspiradora; estimulação intelectual; influência idealizada; e consideração individualizada.

Na TV Jangadeiro, a gerente de jornalismo busca construir uma relação de confiança com a equipe, mantendo comunicação aberta para a discussão de erros, problemas e soluções (motivação inspiradora); incentivar os colaboradores a desafiar o status quo, serem mais proativos na resolução de problemas, e fazer um rodízio de papéis entre as lideranças, para que não se viciem na atuação em um mesmo tipo de programa (estímulo intelectual). A gestora afirmou que apoia as iniciativas criativas, o desenvolvimento profissional e realiza elogios nas reuniões, e por e-mail (consideração individualizada). Sobre a questão da proatividade, explica:

(...) peço para eles não trazerem apenas problemas para mim, mas também as soluções para o problema. Eles já aprenderam isso, chegam para mim e dizem: “amanhã o repórter não vem, mas há uma pessoa no setor que poderá substituí-lo, dobrando sua carga horária." Há três, cinco anos atrás tudo era um problema, (...) e eu busquei ensinar aos meus liderados que (...) tudo se resolve, repassando para eles a necessidade de uma maior serenidade nesses momentos (Entrevista Gerente de Jornalismo da TV Jangadeiro).

Na TV Assembleia, como estratégias de liderança transformacional, constatou-se que a chefe de redação faz uso da motivação inspiradora, onde o líder busca inspirar confiança e respeito (fazer uso da comunicação aberta, saber ouvir, valorizar o outro); do estímulo intelectual, motivando os colaboradores a não se acomodarem na rotina, e na superficialidade; da consideração individualizada, ao tecer elogios, ao acompanhar de perto a atividade de cada colaborador quando não estão seguros ainda na atividade, dando feedback contínuo; e da influência idealizada, quando diz ser ela mesma um exemplo para a equipe, para a qual sempre pontua que para quem tem vontade de trabalhar vai ter sempre espaço.

(...) Não podemos deixar a rotina como comodismo, às vezes a pessoa é tão acostumada em fazer uma entrevista, a apresentar, que não se preocupa em pesquisar. Por exemplo, você tem um programa de entrevistas, por mais que você tenha um entrevistador experiente, um jornalista experiente, se você tem uma bagagem, é sempre bom você olhar que assunto vai discutir com a pessoa, para não ficar só na superficialidade (...). A rotina não pode, portanto, se tornar uma acomodação no dia a dia (Entrevista Chefe de Redação da TV Assembleia).

Depreende-se dos depoimentos do Diretor de Operações e da Editora-chefe da TV O POVO, elementos do estilo de liderança transformacional, no incentivo à autonomia da equipe, à busca das melhores soluções, ao compartilhamento de problemas e delegação de projetos para fomentar o aprendizado (estímulo intelectual); no uso do feedback contínuo, ao destacarem as qualidades da equipe e discutirem o que deu certo ou não (consideração individualizada); e como possuidores de uma experiência maior do que a equipe, atuam como modelos, dando apoio e força constantes para incrementar o programa (influência idealizada). O Diretor da TV O Povo definiu assim seu estilo de liderança:

Acho que meu estilo de liderança é mais do tipo organizacional. Valorizo os processos, a clareza no papel de cada um nesse processo, a otimização de tempo e recursos, a sinergia entre pessoas, setores, áreas... Procuro ser sempre o mais sincero e transparente possível, delegando responsabilidades, transmitindo informações, explicando o sentido e o por quê das coisas. Ouço muito também, gosto de ter feedback de cada ação, grande ou pequena. Olho no olho, sou franco e direto (Entrevista Diretor da TV O Povo).

Afirma a editora-chefe da TV O Povo que é necessário não só delegar tarefas, mas também acompanhar os processos, para gerar aprendizagem:

(...) quando não há esse acompanhamento, geralmente não dá certo, por que realmente eles são muito jovens (...) é importante procurar sempre discutir o que deu certo e o que não deu certo, é isso que eu utilizo aqui. Então (...) também incentivo outros repórteres e produtores, para que quando for percebido algum problema, quando houver alguma coisa a ser compartilhada, que eles façam isso para que haja um processo de aprendizado, não só individual, mas até coletivo, então, coisas que valham a pena ser discutidos em reunião, que é importante para gerar aprendizagem, a gente faz isso (Entrevista Editora-chefe da TV O Povo).

\subsection{Poder e Conflitos}

O Diretor da TV Assembleia e o chefe dos cinegrafistas destacaram que ocorrem conflitos individuais entre os colaboradores em torno do controle criativo do processo de produção, assim como estresse por conta 
Vivianne Pereira Salas Roldan, Augusto Cézar de Aquino Cabral, Maria Naiula Monteiro Pessoa, Rodrigo Bandeira-de-Mello, Sandra Maria dos Santos, Tereza Cristina Batista de Lima

das pressões para elevar o seu valor, o que inibe a criatividade. Alguns colaboradores adquirem forte poder de influência e prestígio associado à sua competência criativa, o que gera conflitos. Há diferenças entre os trabalhadores quanto ao acesso aos recursos disponíveis, pois a TV Assembleia sofre com limitações técnicas, de estrutura física e material.

Os dirigentes da TV O POVO consideraram que existem somente conflitos na empresa relacionados ao poder e prestígio adquirido por determinados colaboradores pela sua competência criativa. Segundo os dirigentes das TVs pesquisadas, não há interferência dos executivos das redes de TVs sobre a autonomia das emissoras, nem conflitos de interesses entre seus dirigentes.

\subsection{Discussão dos Resultados}

Como defendido por autores como Amabile (1997), Csikszentmihalyi (1996, 1999), e Woodman et al. (1993), a criatividade requer um contexto onde deverá ser desenvolvida e transmitida, transformando-se em algo útil. Além de um contexto social favorável, é necessário que haja uma organização ou uma configuração organizacional que permita que a criatividade floresça.

Os resultados desta pesquisa destacam as rotinas jornalísticas inerentes ao processo de produção dos telejornais como parte do domínio de conhecimentos acumulados e compartilhados no meio social televisivo. Como confirmam os gestores da TV Jangadeiro e TV O Povo, essas regras e procedimentos jornalísticos institucionalizados entre os profissionais de TV contribuem para a geração de produtos inovadores, o que está de acordo com o que é defendido por Csikszentmihalyi (1999), que afirma que quanto mais estruturado o domínio, maior a probabilidade de ocorrer a inovação.

No contexto das TVs analisadas, o campo referente ao conjunto de atores envolvidos no processo de produção do telejornal é favorável à inovação pretendida pelos gestores, pois em todas as equipes foi constatado um elevado comprometimento com as novas ideias. Csikszentmihalyi defende que a receptividade do campo é mais importante do que a quantidade de indivíduos capazes de gerar novas ideias (Alencar \& Fleith, 2003).

Constatou-se que os gestores estimulam esse comprometimento por meio de estímulos relacionados à motivação intrínseca, de forma que os colaboradores se sintam envolvidos por um profundo interesse e curiosidade, promovendo um sentido de desafio pessoal (Amabile, 1997) no incentivo às capacidades pessoais dos colaboradores, em termos de discernimento e responsabilidade.

Ao mesmo tempo, o contexto social revelado pela variável clima, tanto pelos dados qualitativos como quantitativos, destacou-se como positivo para todas as TVs. Apesar do posicionamento favorável quanto ao clima apontado para a TV Assembleia, por meio dos resultados do questionário TFI, não se pode dizer que inexistem conflitos, como destacado pelos gestores nas entrevistas.

Verificou-se que a promoção do comprometimento da equipe com as novas ideias, do clima positivo, assim como da capacidade de resiliência, de constituir contatos externos, e de aprender com os próprios erros, é realizada pelos gestores por meio de estratégias de liderança transformacional e transacional (recompensas), destacando-se a primeira como a principal geradora desses fatores, conforme a análise de regressão.

As estratégias de liderança transformacional se destacaram neste estudo para a produção da flexibilidade necessária ao processo criativo referente à geração de ideias e desenvolvimento dos programas (Bonner, 2009). A atuação da liderança nas TVs analisadas, em especial na TV O Povo e TV Jangadeiro, conseguem promover a resiliência e capacidade de aprendizagem, para que as equipes sejam capazes de lidar positivamente com a incerteza inerente à elaboração do produto televisivo, pela instabilidade da demanda e a probabilidade de ocorrência de fatos inesperados, que podem provocar alterações de conteúdo e tempo de programação (Bendassolli, Wood, Kirschbaum, \& Cunha, 2009; Becker, Bergener, Schwehm \& Voigt, 2011).

Para lidar com a exigência de controle e previsibilidade, referentes ao formato pré-determinado do programa de TV, ao tempo de execução, e à obediência a uma linha editorial (Ekström, 2002; Bonner, 2009), os gestores das TVs estudadas fazem uso das estratégias de liderança transacional. Por meio delas, reduzem os riscos de ordem criativa (aceitação dos telespectadores) e operacional (financeira, técnica, organizacionais ou de pessoal), pela constituição de uma plataforma de entendimento e visão compartilhada. Como destacado por Becker et al., (2011), constatou-se em todas as TVs uma alta intensidade de comunicação, com o uso de reuniões diárias, o que favorece a interatividade e a colaboração necessária entre os atores envolvidos para o desenvolvimento dos programas jornalísticos.

Como destacado por Loon e Hemmingway (2005) e Zaheer e Soda (2009), foram encontradas equipes polivalentes nas TVs analisadas, compostas por produtores, editores de texto, editores de imagem, entre outros, havendo possibilidade de ocorrer rotatividade entre funções, como visto na TV Jangadeiro.

Por meio desta pesquisa, foram identificadas ainda certas particularidades de cada TV que influenciam a gestão e o desempenho das equipes, como: a disponibilidade de recursos (financeiros, tecnológicos, entre outros) que se destacaram como escassos na TV Estatal e TV Educativa; o tamanho da estrutura da TV; a maturidade dos membros da equipe; a frequência com que a linha editorial é modificada, destacando-se neste estudo a TV Estatal, cuja linha editorial varia a cada mudança da Mesa Diretora; e o enfoque editorial da rede 
Estilo de liderança e desempenho criativo em equipes de telejornalismo: um estudo em emissoras de TV cearenses

televisiva à qual a emissora de TV está vinculada, que no caso da TV Jangadeiro se configurou como prejudicial, tendo em vista sua finalidade comercial, por exigir maior esforço da equipe para elevar a audiência.

\section{Conclusões e Recomendações}

O estudo permitiu discutir a gestão da criatividade no contexto das organizações culturais, por meio de uma abordagem da pesquisa multiparadigmática, com uso de estratégias quantitativas e qualitativas de coleta e análise de dados. Sobre o desempenho criativo das equipes, as equipes das TVs analisadas se enquadraram como "Equipe dos sonhos", que buscam ir além do dos resultados esperados. Apesar disso, nas entrevistas, o Diretor da TV Assembleia e os dirigentes da TV Povo destacaram estarem parcialmente satisfeitos com o desempenho de suas equipes.

Tanto pela análise quantitativa, como qualitativa, verificou-se que os gestores das TVs analisadas fazem uso combinado das estratégias do estilo de liderança transacional e transformacional para conduzirem suas equipes.

A análise quantitativa sugere que o estilo de liderança transformacional é o que mais contribui para a melhoria dos fatores derivados da ação direta do líder, como também, para a melhoria do resultado das equipes de telejornalismo quanto à produtividade, criatividade e gerenciamento do conhecimento. Em especial, a análise qualitativa revelou que a liderança transformacional está mais relacionada com a promoção dos seguintes fatores: clima; resiliência; ideias próprias; ativação em rede; e aprendizado vindo da experiência. Por sua vez, demonstrou ainda que a liderança transacional está mais relacionada com os fatores plataforma de entendimento e visão compartilhada.

A utilização de estratégias de liderança transacional traduz a necessidade de previsibilidade e controle inerentes ao processo de produção dos programas televisivos de cunho jornalístico, sendo as reuniões o principal mecanismo utilizado pelas lideranças das TVs para a promoção da plataforma de entendimento e visão compartilhada. A produção dos programas jornalísticos também requer flexibilidade, o que explica o uso das estratégias de liderança transformacional pelos gestores. Dentre essas estratégias, em todas as TVs foi constatado o uso do empowerment e do estímulo à aprendizagem.

O próprio contexto da indústria televisiva de instabilidade da demanda, risco elevado e inovação contínua exige das equipes de telejornalismo um desempenho criativo além do esperado, tornando necessário o uso da liderança transformacional para aumentar a eficácia da liderança transacional.

Por meio deste estudo, constataram-se os benefícios trazidos pelo uso da abordagem multiparadigmática de pesquisa, percebendo-se que os resultados de um método complementaram os resultados do outro, contribuindo para uma melhor compreensão do fenômeno analisado. Como limitações desta pesquisa destacase o não detalhamento da divergência da percepção entre os líderes e liderados. Para estudos futuros sugere-se o preenchimento dessa lacuna, e o uso de variáveis de nível organizacional na análise quantitativa para a melhor compreensão de sua influência sobre o desempenho criativo das equipes.

\section{Notas}

1- Agradecemos aos avaliadores da revista pelo precioso trabalho de revisão realizado no artigo.

\section{Referências}

Albarran, A. B. (2006). Historical Trends and Patterns in Media Management Research. In Albarran, A. B., ChanOlmsted, S. M., \& Wirth, M. O. (Orgs.). Handbook of media management and economics (Cap. 1, pp. 16-22). New Jersey: Lawrence Erlbaum Associates.

Alencar, E. M. L. S. de, \& Fleith, D. de S. (2003, abril). Contribuições teóricas recentes ao estudo da criatividade. Psicologia: teoria e pesquisa, 19 (1), 1-8.

Amabile, T. M. (1997, março). Entrepreneurial creativity through motivational synergy. Journal of Creative Behavior, 31(1), 18-26.

Assembleia Legislativa do Estado do Ceará. (2012). TV Assembleia. Recuperado em 17 março, 2012, de http://www.al.ce.gov.br/index.php/canal-assembleia

Band. (2011, novembro 18). TV Jangadeiro anuncia filiação à Band. Recuperado em 17 março, 2012, de http://www.band.com.br/noticias/brasil/noticia/?id=100000469539

Bardin, L. (2003). Análise de Conteúdo. Lisboa: Edições 70.

Bass, B. M. (1985). Leadership and performance beyond expectations. New York: Free Press.

Bass, B. M., \& Avolio, B. J. (1994). Improving organizational effectiveness through transformational leadership. Thousand Oaks, CA: Sage. 
Vivianne Pereira Salas Roldan, Augusto Cézar de Aquino Cabral, Maria Naiula Monteiro Pessoa, Rodrigo Bandeira-de-Mello, Sandra Maria dos Santos, Tereza Cristina Batista de Lima

Becker, J., Bergener, K., Schwehm, M., \& Voigt, M. (2011). Confirming BPM Theory in creative industry context: a case study in the german tv industry. European Conference On Information Systems, Helsinki, Finland, 19.

Bendassolli, P. F., Wood, T., Jr., Kirschbaum, C., \& Cunha, M. P. (2009). Indústrias criativas no Brasil. São Paulo: Atlas.

Björk, J., Boccardelli, P., \& Magnusson, M. (2010, dezembro). Ideation Capabilities for Continuous Innovation. Creativity and innovation management, 19 (4), 385-396.

Bonner, W. (2009). Jornal Nacional: modo de fazer. Rio de Janeiro: Editora Globo.

Bryman, A. (1998). Liderança nas organizações. In Clegg, S.; Hardy, C.; Nord, W. (Org.). Handbook de estudos organizacionais: ação e análises organizacionais (v.3, Cap.10, pp. 257-281). São Paulo: Atlas.

Bryman, A. (2011). Mission accomplished? Research methods in the first five years of Leadership. Leadership, $7(1), 73-83$.

Caves, R. E. (2003). Contracts between art and commerce. The Journal of Economic Perspectives, 17 (2), $73-84$. Csikszentmihalyi, M. (1996). Creativity. New York: HarperCollins.

Csikszentmihalyi, M. (1999). Implications of a systems perspective for the study of creativity. In Sternberg, R. J. (Org.), Handbook of creativity (pp. 313-335). New York: Cambridge University Press.

Daymon, C.(2000). Culture formation in a New Television Station: a multi-perspective analysis. British Journal of Management, 11 (2), 121-135.

Defillippi, R., Grabher, G., \& Jones, C. (2007). Introduction to paradoxes of creativity: managerial and organizational challenges in the cultural economy. Journal of Organizational Behavior, 28 (5), $511-521$.

Dionne, S. D., Yammarino, F. J., Atwater, L. E., \& Spangler, W. D. (2004). Transformational leadership and team performance. Journal of Organizational Change Management, 17 (2), 177-193.

Eisenberger, R., \& Shanock, L. (2003). Rewards, intrinsic motivation, and creativity: A case study of conceptual and methodological isolation. Creativity Research Journal, 15 (2), 121-130.

Ekström, M. (2002). Epistemologies of TV journalism: a theoretical framework. Journalism, 3(3), $259-282$.

Gluck, M., \& Sales, M. R. (2008). The future of television: advertising, technology and the pursuit of audiences. Recuperado em 8 janeiro, 2011, de http://learcenter.org/pdf/FutureofTV.pdf

Gomes, I. M. M. (2006, agosto). Telejornalismo de qualidade: pressupostos teórico-metodológicos para análise. Revista da Associação Nacional dos Programas de Pós-Graduação em Comunicação, 1-22. Recuperado em 7 abril, 2012, de http://telejornalismo.org/wp-content/uploads/2010/05/Itania_Telejornalismo-dequalidade_ecomp\%C3\%B3s.pdf

Gong, Y., Huang, J., \& Farh, J. (2009). Employee learning orientation, transformational leadership, and employee creativity: the mediating role of employee creative self-efficacy. Academy of Management journal, 52(4), 765778.

Hesmondhalgh, D., \& Baker, S. (2008). Creative Work and Emotional Labour in the Television Industry. Theory Culture Society, 25 (7-8), 97-118.

Jangadeiro Online. (2012b). TV Jangadeiro 20 anos. Recuperado em 17 março, 2012, de http://www.youtube.com/watch?v=IT6URugwNbc\&feature=related

Jung, D. I., Chow, C., \& Wu, A. (2003). The role of transformational leadership in enhancing organizational innovation: Hypotheses and some preliminary findings. The Leadership Quarterly, 14 (4-5), 525-544.

Jung, D., Chow, C., \& Wu, A. (2008). Towards understanding the direct and indirect effects of CEOs' transformational leadership on firm innovation. The Leadership Quarterly, 19(1), 582-594.

Kearney, E., \& Gebert, D. (2009). Managing diversity and enhancing team outcomes: the promise of transformational leadership. Journal of applied psychology, 94 (1), 77-89.

Lee, D. (2011) Networks, cultural capital and creative labour in the British independent television industry. Media, Culture \& Society, 33 (4), $549-565$.

Lewis, M. W., Grimes, A. J. (2007). Metatriangulação: construção teórica com base em paradigmas múltiplos. In Caldas, Miguel P.; Bertero, Carlos Osmar (org.). Teoria das organizações (Parte 1, Cap. 3). São Paulo: Atlas.

Loon, J. V., \& Hemmingway, E. (2005). Organisations, identities and technologies in innovation management: the rise and fall of Bi-Media in the BBC East Midlands. Intervention Research, 1 (2), 125-147.

Mackinnon, D.W. (1965). Personality and the realization of creative potential. American Psychologist, 20, 273281.

Mumford, M. D., Scott, G. M., Gaddis, B., \& Strange, J. M. (2002). Leading creative people: orchestrating expertise and relationships. The Leadership Quarterly, 13 (6), 705-750. 
Pieterse, A. N., Knippenberg, D. V., Schippers, M., \& Stam, D. (2010). Transformational and transactional leadership and innovative behavior: the moderating role of psychological empowerment. Journal of Organizational Behavior, 31 (4), 609-623.

Reca, Á. A. (2006). Issues in Media Product Management. In Albarran, A. B.; Chan-Olmsted, S. M.; Wirth, M. O. (org.). Handbook of media management and economics (Cap. 9, pp. 181-201). New Jersey: Lawrence Erlbaum Associates.

Rickards, T., \& Clark, M. (2006). Dilemmas of Leadership. New York: Routledge.

Rickards, T., \& Moger, S. (2000, dezembro). Creative leadership processes in project team development: an alternative to Tuckman's model. British journal of Management, 11 (4), 273-283.

Souza, J. C. A. (2004). Gêneros e formatos na televisão brasileira. São Paulo: Summus editorial.

Van Woerkom, M., Croon, M. (2009). The relationships between team learning activities and team performance. Personnel Review, 38 (5), 560-577.

Woodman, R. W., Sawyer, J. E., \& Griffin, R. W. (1993). Toward a theory of organizational creativity. Academy of Management Review, 18(2), 293-321.

Yin, R. K. (2003). Estudo de caso: planejamento e métodos (2a ed.). Porto Alegre: Bookman.

Zaheer, A.; Soda, G. (2009, março). Network evolution: the origins of structural holes. Administrative Science Quarterly, 54 (1), 1-31. 